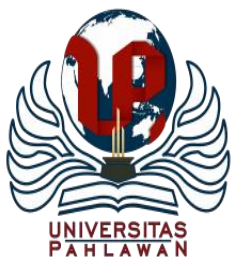

Edukatif : Jurnal Ilmu Pendidikan Volume 1 Nomor 2 Tahun 2019 Halaman 88- 96 EDUKATIF: JURNAL ILMU PENDIDIKAN

Research \& Learning in Education

https://edukatif.org/index.php/edukatif/index

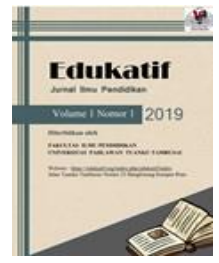

\title{
PELAKSANAAN AKTIVITAS PENGEMBANGAN DIRI OLAHRAGA BOLA VOLI MINI DI SD 007 KAMPUNG TELUK MERBAU
}

\author{
Iska Noviardila ${ }^{1}$ \\ Progam Studi Pendidikan Jasmani dan Kesehatan, Universitas Pahlawan Tuanku Tambusai ${ }^{1}$ \\ e-mail : iska@ universitaspahlawan.ac.id $^{1}$
}

\begin{abstract}
Abstrak
Berdasarkan hasil survei tentang keberadaan kegiatan ekstrakurikuler bola voli mini di SD Negeri 007 Kampung Teluk Merbau Kec. Dayun Kab. Siak secara utuh perlu kiranya diadakan penelitian untuk dapat mengungkapkan dan mencari solusi terbaik tentang sebab-sebab belum tercapainya prestasi olahraga pada cabang bolavoli mini di SD Negeri 007 Kampung Teluk Merbau Kec. Dayun Kab. Siak, serta untuk mendapatkan data tentang pelaksanaan kegiatan ekstrakurikuler olahraga bolavoli mini. Metode penelitian ini adalah berbentuk deskriptif, populasi berjumlah 48 orang, menggunakan teknik total sampling keseluruh menjadi sampel penelitian. Data motivasi siswa terhadap kegiatan ekstrakurikuler permainan bolavoli mini adalah berupa angket yang disebarkan kepada siswa itu. Skala pengukuran yang dilakukan adalah skala Guttman. Hasil analisis data dan interprestasi dari hasil penelitian mengindikasikan bahwa; (1). secara keseluruhan tingkat capaian program latihan yang diperoleh sebesar 51,7\%. Artinya bahwa tingkat capaian Motivasi siswa yang ada berada pada klasifikasi Kurang. (2). Capaian dukungan orang tua yang diperoleh sebesar 64,7\%, artinya bahwa tingkat capaian dukungan orang tua terhadap kegiatan ekstrakurikuler bolavoli mini pada klasifikasi Cukup. Hasil dari penelitian ini mengimplikasikan bahwa motivasi siswa dan dukungan orang tua ternyata menjadi salah satu factor penentu keberlangsungan ektrakulikuler bola voli mini di SD Negeri 007 Kampung Teluk Merbau Kec. Dayun Kab. Siak.
\end{abstract}

Kata Kunci: Aktivitas Pengembangan Diri Olahraga Bola Voli Mini, Motivasi siswa, Dukungan Orang Tua

\begin{abstract}
Based on the results of a survey about the existence of mini volleyball extracurricular activities in 007 Public Elementary School, Teluk Merbau Village, Kec. Dayun Kab. Full research needs to be held to be able to reveal and find the best solutions about the causes of non-achievement of sports achievements at the mini volleyball branch in 007 Public Elementary School, Teluk Merbau Village, Kec. Dayun Kab. Siak, as well as getting data on the implementation of mini volleyball sports extracurricular activities. The method of this research is descriptive, the population is 48 people, using the total sampling technique throughout the study sample. Student motivation data on extracurricular activities in mini volleyball games are in the form of questionnaires distributed to students. The measurement scale taken is the Guttman scale. The results of data analysis and interpretation of research results indicate that; (1) overall the level of achievement of the training program obtained was 51.7\%. This means that the level of achievement of the motivation of existing students is in the classification of Less. (2) The achievement of parental support obtained was 64.7\%, meaning that the level of achievement of parents' support for mini volleyball extracurricular activities in the classification was Enough. The results of this study imply that student motivation and parental support turned out to be one of the determinants of the continuity of extracurricular mini volleyball in 007 Public Elementary School, Teluk Merbau Village, Kec. Dayun Kab. Siak
\end{abstract}

Keywords: Self volleyball mini self development activities, Student motivation, Parental support

@Edukasi: Jurnal Ilmu Pendidikan FIP UPTT 2019

$\triangle$ Corresponding author :

Address :

Email : iska@universitaspahlawan.ac.id

Phone
ISSN 2656-8063 (Media Cetak) ISSN 2656-8071 (Media Online) 
89 Pelaksanaan aktivitas pengembangan diri olahraga bola voli mini di SD 007 Kampung Teluk Merbau- Iska Noviardila

\section{PENDAHULUAN}

Pendidikan adalah suatu usaha atau kegiatan dijalankan dengan sengaja, teratur dan terencana dengan maksud mengubah atau mengembangkan prilaku yang diinginkan. Sekolah sebagai lembaga formal merupakan sarana dalam rangka pencapaian tujuan pendidikan tersebut. Dalam pendidikan formal belajar menunjukan adanya perubahan yang bersifat positif sehingga pada tahap akhir akan didapat keterampilan, kecakapan dan pengetahuan, baru. Hasil dari proses belajar tersebut tercermin dalam pretasi belajar.

Pendidikan yang dilaksanakan sekolah harus dapat berperan dalam masyarakat yang sedang berkembang pada saat ini, yaitu manusia yang bertaqwa kepada Tuhan Yang Maha Esa, berbudi luhur, terampil serta sehat jasmani dan rohani. Hal ini sesuai dengan tujuan pendidikan nasional yang dituangkan dalam Undang-Undang No. 20 Tahun 2003 halaman 8 tentang sistem pendidikan nasional yang bertujuan sebagai berikut:

"Pendidikan Nasional berfungsi mengembangkan kemampuan dan membentuk watak serta peradaban bangsa yang bermartabat dalam rangka mencerdaskan kehidupan bangsa, bertujuan untuk berkembangnya potensi peserta didik agar menjadi manusia yang beriman dan bertaqwa kepada Tuhan Yang Maha Esa, berakhlak mulia, sehat, berilmu, cakap, kreatif, mandiri, dan menjadi warga negara yang demokratis serta bertanggung jawab".

Berdasarkan uraian tersebut jelaslah bahwa pendidikan yang dilaksanakan di sekolah adalah sebagai alat untuk meningkatkan kualitas manusia itu sendiri. Mengembangkan aspek tingkah laku peserta didik untuk mendapatkan sesuai dengan yang diharapkan, maka sekolah turut bertanggung jawab.

Kegiatan ekstrakurikuler penting untuk dikembangkan setiap murid. Dengan kegiatan ekstrakurikuler ini maka akan memberi kesempatan kepada murid untuk mengekspresikan minat dan bakatnya.

Pengembangan diri bukan merupakan mata pelajaran yang harus diasuh oleh guru, pengembangan diri bertujuan memberi kesempatan kepada peserta didik untuk mengembangkan dan mengekspresikan diri sesuai dengan kebutuhan, bakat, dan minat setiap peserta didik sesuai dengan kondisi sekolah. Kegiatan pengembangan diri difasilitasi dan atau dibimbing oleh konselor, guru, atau tenaga kependidikan yang dapat dilakukan dalam bentuk kegiatan ekstrakurikuler.

Kegiatan ekstrakurikuler jika
dijalankan dengan baik sangat besar
pengaruhnya terhadap dunia pendidikan sekolah. Dengan begitu sekolah hendaknya melaksanakan program ini secara seimbang dan juga memperhatikan kondisi lingkungan. Mengingat betapa besarnya manfaat kegiatan ekstrakurikuler apabila kegiatan dapat dilaksanakan dengan baik pada didik untuk mencapai prestasi yang maksimal, untuk itulah diharapkan pihak sekolah dapat mengembangkan kegiatan ekstrakurikuler ini dan dapat membinanya secara baik. Pembinaan ini harus dilakukan dengan memperhatikan potensi, dan minat dari peserta didik secara menyeluruh, hal ini sesuai dengan 
90 Pelaksanaan aktivitas pengembangan diri olahraga bola voli mini di SD 007 Kampung Teluk Merbau- Iska Noviardila

yang tercantum pada UU No. 3 Th 2005 tentang Sistem Keolahragaan Nasional Pasal 25 ayat 4 yang menyebutkan bahwa: "Pembinaan dan pengembangan olahraga pendidikan dilaksanakan dengan memperhatikan potensi, kemampuan, minat, dan bakat peserta didik secara menyeluruh, baik melalui kegiatan intrakurikuler maupun ekstrakurikuler." Dari sekian banyak mata pelajaran yang melaksanakan kegiatan ekstrakurikuler, diantaranya adalah kegiatan ekstrakurikuler pada mata pelajaran Pendidikan jasmani olahraga dan kesehatan. Kegiatan ekstrakurikuler pada mata pelajaran Penjaskes ini dibagi dalam kelompok cabang olahraga, dan salah satunya kegiatan ekstrakurikuler mata pelajaran penjas Pada cabang olahraga bola voli mini. Kegiatan ekstrakurikuler mata pelajakes adalah cabang olahraga bola voli mini sangat banyak digemari oleh peseerta didik.

Pembinaan kegiatan ekstrakurikuler olahraga bolavoli mini bertujuan untuk meningkatkan prestasi yang diarahkan terciptanya atlet bolavoli mini yang berkualitas. Untuk meningkatkan kualitas atlet secara maksimal dapat dilakukan dengan suatu pembinaan dan latihan sejak usia dini, Harsono (1995:4) menyebutkan : "1) Perlu diupayakan pembinaan atilt sejak usia dini, 2) Adanya latihan-latihan yang teratur dan latihannya bertahap dengan terprogram, 3) Sistem kompetisi yang teratur sesuai dengan tingkat dan frekeunsinya baik secara vertikal maupun horizontal, 4) Menyediakan sarana dan prasaran olahraga."

Dari kutipan tersebut dapat disimpulkan, bahwa untuk mencapai mutu dan prestasi maksimal tentunya harus melalui suatu proses, mulai sejak dini. Agar prestasi yang diharapkan dapat tercapai dengan baik sehingga meningkatkan kualitas para atlet itu sendiri sebagaimana yang tercantum dalam GBHN TAP MPR RI yang menjelaskan bahwa: "Untuk menumbuhkan budaya olahraga guna meningkatkan kualitas manusia Indonesia sehingga memiliki tingkat kesehatan dan kebugaran yang cukup, yang dimulai sejak usia dini melalui pendidikan olahraga di sekolah".

Pembinaan ekstrakurikuler cabang olahraga bolavoli mini ini tidaklah mudah karena masih banyak permasalahan yang sampai saat ini belum terpecahkan, diantaranya masih minimnya sarana prasarana yang digunakan, belum maksimalnya pembinaan, kurangnya motivasi peserta didik, fungsi dan tugas guru sebagai pelatih, tidak adanya program latihan, latar belakang pendidikan guru dan kualifikasi guru sebagai pelatih, kurangnya sumber dana yang dimiliki, kurangnya perhatian pemerintah, dan kurangnya adanya dukungan orang tua, sekolah dan masyarakat.

Salah satu sekolah yang menyelenggarakan kegiatan ekstrakurikuler Bolavoli mini ini adalah SD Negeri 007 Kampung Teluk Merbau Kec. Dayun Kab. Siak, yang mana kegiatan ekstrakurikuler yang ada di SD Negeri 007 Kampung Teluk Merbau Kec. Dayun Kab. Siak khususnya dalam pembinaan juga belum mampu menunjukan prestasi yang diharapkan, dan belum mampu menjadi penyokong prestasi para atlet dan insan olahraga. Seharusnya pendidikan yang dilakukan di sekolah yang dimulai sejak dini 
91 Pelaksanaan aktivitas pengembangan diri olahraga bola voli mini di SD 007 Kampung Teluk Merbau- Iska Noviardila

bisa memberikan kontribusi untuk menghasilkan atlet yang berprestasi.

Melihat keberadaan kegiatan ekstrakurikuler bolavoli mini di SD Negeri 007 Kampung Teluk Merbau Kec. Dayun Kab. Siak secara utuh perlu kiranya diadakan penelitian yang mendalam untuk dapat mengungkapkan dan mencari solusi terbaik tentang sebab-sebab belum tercapainya prestasi olahraga khususnya pada cabang bolavoli mini di SD Negeri 007 Kampung Teluk Merbau Kec. Dayun Kab. Siak, serta untuk mendapatkan data yang akurat tentang pelaksanaan kegiatan ekstrakurikuler olahraga bolavoli mini di SD Negeri 007 Kampung Teluk Merbau Kec. Dayun Kab. Siak. Untuk itulah maka penulis ingin meneliti tentang Pelaksanaan Ekstrakurikuler Bolavoli Mini di SD Negeri 007 Kampung Teluk Merbau Kec. Dayun Kab. Siak.

\section{METODE PENELITIAN}

Jenis penelitian ini berbentuk deskriptif untuk memberikan pengertian dan menginterprestasikan data bagai mana adanya. Penelitian ini bertujuan untuk mengungkapkan bagaimana pelaksanaan kegiatan ekstrakurikuler cabang olahraga bola voli mini pada SD Negeri 007 Kampung Teluk Merbau Kec. Dayun Kab. Siak. Penelitian ini dilaksanakan pada SD Negeri 007 Kampung Teluk Merbau Kec. Dayun Kab. Siak pada bulan Juni 2018. Populasi dalam penelitian ini adalah peserta didik SD Negeri 007 Kampung Teluk Merbau Kec. Dayun Kab. Siak yang aktif mengikuti kegiatan ekstrakurikuler bolavoli mini yang berjumlah 48 orang, terdiri

dari 23 orang putra dan 25 orang putri. Untuk lebih jelasnya bisa dilihat pada tabel 3.1 berikut:

Tabel 1. Populasi Penelitian

\begin{tabular}{|c|c|c|c|c|}
\hline No & Kelas & Putera & Puteri & Jumlah \\
\hline 1 & IV & 7 & 5 & 12 \\
\hline 2 & V & 8 & 11 & 19 \\
\hline 3 & VI & 8 & 9 & 17 \\
\hline \multicolumn{2}{|c|}{ Jumlah } & 23 & 25 & 48 \\
\hline
\end{tabular}

Mengingat populasi relatif sedikit maka seluruh populasi dijadikan sample yaitu sebanyak 48 orang. Jenis data dalam penelitian ini adalah data primer yang diperoleh langsung dari responden dan data sekunder. Sumber data dalam penelitian ini adalah dari responden siswa SD Negeri 007 Kampung Teluk Merbau Kec. Dayun Kab. Siak yang ikut dalam kegiatan ekstrakurikuler bolavoli mini dengan cara mengisi angket sesuai dengan data yang diperlukan.

Untuk memperoleh data mengenai motivasi siswa terhadap kegiatan ekstrakurikuler permainan bolavoli mini maka alat yang digunakan untuk mengumpulkan data tersebut adalah berupa angket yang disebarkan kepada siswa itu. Namun terlebih dahulu diuji cobakan kepada siswa yang tidak terpilih menjadi sampel.

Angket yang disebarkan berisi pertanyaan-pertanyaan kemudian disusun berdasarkan indikator dari masalah yang diteliti yakni motivasi siswa terhadap ekstrakurikuler permainan bolavoli mini. Angket yang digunakan merupakan angket tertutup (angket berstruktur), yaitu angket yang disajikan dalam bentuk sedemikian rupa sehingga responden diminta untuk memilih salah satu jawaban yang tersedia. 
92 Pelaksanaan aktivitas pengembangan diri olahraga bola voli mini di SD 007 Kampung Teluk Merbau- Iska Noviardila

Skala pengukuran yang dilakukan adalah skala Guttman dengan dua alternatif jawaban yaitu: "YA" dan "TIDAK". Sebagaimana yang diungkapkan Riduwan (2005:16), yang menjelaskan bahwa: "Skala Guttman adalah skala yang digunakan unutk jawaban yang bersifat jelas (tegas) dan konsisten". Untuk butir jawaban "YA" diberi skor 1, sedangkan jawaban "TIDAK" diberi skor 0 .

Berdasarkan penelitian deksriptif, Arikunto (1990) mengatakan data yang terkumpul akan dianalisis dengan menggunakan teknik distributif frekwensi atau teknik presentase dengan menggunakan rumus sebagai berikut:

$\mathrm{P}=\underline{\mathrm{F}} \times 100 \%$

$\mathrm{N}$

Keterangan :

$\mathrm{P}=$ Persentase

$\mathrm{F}=$ Frekwensi atau jumlah skor

$\mathrm{N}=$ Total jumlah responden

Untuk menentukan kategori penelitian, yang digunakan adalah klasifikasi, yaitu:

90-100 : Sangat Baik

$80-89 \quad$ : Baik

65-79 : Cukup

55-64 : Kurang

$0-54$ : Kurang Sekali

\section{HASIL DAN PENELITIAN}

Sebelum dilakukan analisis terhadap data "Pelaksanaan Ekstrakurikuler Bolavoli Mini di SD Negeri 007 Kampung Teluk Merbau Kec. Dayun Kab. Siak". Yang ditinjau dari aspek motivasi siswa serta dukungan orang tua. Maka dilakukan verifikasi (seleksi) terhadap data yang telah diperoleh.

Tujuan dilakukan verifikasi data adalah apabila ada data yang tidak lengkap yang diisi oleh responden dalam instrumen, maka data tersebut tidak dapat diolah. Kriteria lengkapnya data yang diisi responden terhadap instrumen apabila seluruh pertanyaan dijawab sesuai dengan instruksi yang ada dalam instrumen tersebut. Berdasarkan hasil verifikasi terhadap data yang diperoleh, ternyata semua data dapat diolah. Deskripsi data yang dilakukan dalam penelitian ini adalah untuk melihat karakteristik distribusi data dari variabel pertanyaan yang meliputi aspek tentang Sarana dan prasarana, motivasi guru, dan dukungan orang tua.

Untuk melihat keadaan motivasi siswa dalam kegiatan ekstrakurikuler bolavoli mini di SD Negeri 007 Kampung Teluk Merbau Kec. Dayun Kab. Siak terdapat 12 butir pertanyaan yang terdiri dari indikator Antusias, disiplin, dan minat siswa, adapun hasil dari jawaban responden terhadap pertanyaan mengenai Motivasi siswa. Dari hasil penelitian terlihat bahwa dari 12 pertanyaan, skor tertinggi adalah pada butir pertanyaan No 11 yaitu Menurut ananda apakah kegiatan ekstrakurikuler dapat melatih agar siswa dapat aktif dan kreatif, ini terbukti dengan jawaban responden yang mencapai skor 34 dan dengan tingkat capaian 70\%, sedangkan skor terendah terdapat pada butir pertanyaan No 3, yang Apakah Guru/ pelatihh ekstrakurikuler bolavoli mini selalu menjelaskan metode latihan yang baru, skor yang didapat adalah 17 dan dengan tingkat 
93 Pelaksanaan aktivitas pengembangan diri olahraga bola voli mini di SD 007 Kampung Teluk Merbau- Iska Noviardila

capaian $35 \%$. Ini artinya walaupun siswa telah mengikuti kejuaraan bola voli mini yang ada di SD Negeri 007 Kampung Teluk Merbau Kec. Dayun Kab. Siak sudah sangat baik, namun belum semua siswa mengisi waktu senggang dengan bermain bolavoli mini yang dapat digunakan untuk meningkatkan kemapuan individu seseorang.

Tabel 2

Deskripsi Hasil Data Motivasi siswa

\begin{tabular}{|c|c|c|c|c|}
\hline No & $\begin{array}{c}\text { Kategori } \\
\text { Jawaban }\end{array}$ & $\begin{array}{c}\text { Jumlah } \\
\text { Jawaban } \\
\text { Responden }\end{array}$ & $\begin{array}{c}\text { Persentase } \\
(\%)\end{array}$ & $\begin{array}{c}\text { Tingkat } \\
\text { Capaian }\end{array}$ \\
\hline 1 & Ya & 298 & 51,7 & $51,7 \%$ \\
\cline { 1 - 3 } 2 & Tidak & 278 & 48,3 & (Kurang) \\
\hline \multicolumn{2}{|c|}{ Jumlah } & 676 & 100 & \\
\hline
\end{tabular}

Pada Tabel 5 dapat diketahui bahwa dari 48 orang responden dan dari 12 buah pernyataan, total jawaban "Ya" adalah sebanyak 298 atau 51,7\% dan total jawaban "Tidak" adalah 278 atau 48,7\%. Secara keseluruhan tingkat capaian Motivasi siswa yang diperoleh dari 48 orang responden untuk 12 butir pernyataan adalah sebesar $51,7 \%$, itu artinya bahwa tingkat capaian Motivasi siswa dalam kegiatan ekstrakurikuler bolavoli mini yang ada di SD Negeri 007 Kampung Teluk Merbau Kec. Dayun Kab. Siak berada pada klasifikasi kurang.

Untuk melihat dukungan orang tua terhadap kegiatan ekstrakurikuler bolavoli mini di SD Negeri 007 Kampung Teluk Merbau Kec. Dayun Kab. Siak penulis memberikan 10 butir pertanyaan yang terdiri dari indikator perhatian dan peranan orang tua terhadap keberhasilan anaknya 5 butir (Pertanyaan No 26-30), indikator tugas dan kewajiban orang tua terdiri dari 4 butir pertanyaan (Pertanyaan No 31-34), dan dari indikator hubungan orang tua dengan anak dengan guru yang memotivasi latihan anak 1 butir pertanyaan yaitu no soal 35 . Jadi total pertanyaan

Dari hasil penelitian frekuensi terlihat bahwa dari 10 pertanyaan, skor tertinggi adalah dari butir pertanyaan No 1 sampel memberikan jawaban yang besar yaitu dengan skor 39 dengan tingkat capaian $81,25 \%$, ini berarti atlet bolavoli mini di SD Negeri 007 Kampung Teluk Merbau Kec. Dayun Kab. Siak Untuk meningkatkan prestasi apakah orang tua meminta durasi untuk berlatih sebanyak 3-4 kali dalam seminggu, sedangkan skor terendah terdapat pada butir pertanyaan No 3 yaitu Sebelum latihan, apakah saudara disuruh untuk berdoa oleh orang tua dengan skor 13 dan dengan tingkat capaian 54,16\%. Ini artinya walaupun orang tua mengharapkan anaknya berprestasi tinggi dalam olahraga bolavoli mini, namun secara langsung orang tua belum bisa mengarahkan agar di samping berusaha perlu juga didukung dengan doa.

\section{Tabel 3}

Deskripsi Hasil Data Dukungan Orang Tua

\begin{tabular}{|c|c|c|c|c|}
\hline No & $\begin{array}{c}\text { Kategori } \\
\text { Jawaban }\end{array}$ & $\begin{array}{c}\text { Jumlah } \\
\text { Jawaban } \\
\text { Responden }\end{array}$ & $\begin{array}{c}\text { Persentase } \\
(\%)\end{array}$ & $\begin{array}{c}\text { Tingkat } \\
\text { Capaian }\end{array}$ \\
\cline { 1 - 3 } 1 & Ya & 311 & 64,79167 & \multirow{2}{*}{$\mathbf{6 4 , 7} \%$} \\
(Cukup)
\end{tabular}

Pada Tabel 7 dapat diketahui bahwa dari 48 orang responden dan dari 10 buah pertanyaan, total jawaban "Ya" adalah sebanyak 311 atau $64,79 \%$. Dan total jawaban 
94 Pelaksanaan aktivitas pengembangan diri olahraga bola voli mini di SD 007 Kampung Teluk Merbau- Iska Noviardila

“Tidak" adalah sebanyak 167 atau 34,79\%. Secara keseluruhan tingkat capaian dukungan orang tua yang diperoleh dari 48 orang responden untuk 10 butir pertanyaan adalah sebesar $64,7 \%$, itu artinya bahwa tingkat capaian dukungan orang tua terhadap kegiatan ekstrakurikuler bolavoli mini yang ada di SD Negeri 007 Kampung Teluk Merbau Kec. Dayun Kab. Siak berada pada klasifikasi Cukup.

Berdasarkan hasil penelitian yang telah diuraikan, motivasi siswa, dan dukungan orang tua merupakan faktor yang mendukung pembinaan ekstrakurikuler bolavoli mini di SD Negeri 007 Kampung Teluk Merbau Kec. Dayun Kab. Siak.

Dapat dilihat secara keseluruhan tingkat capaian program latihan yang diperoleh sebesar 51,7 \%. Artinya bahwa tingkat capaian Motivasi siswa yang ada di SD Negeri 007 Kampung Teluk Merbau Kec. Dayun Kab. Siak berada pada klasifikasi Kurang. Menurut Sudjana (1989:129) bahwa klasifikasi tingkat capaian antara $65-79 \%$ berada pada klasifikasi Cukup.

Motivasi adalah hal yang sangat penting dalam sebuah kegiatan, karena itu merupakan sebuah pendorong unuk berbuat. Hal ini sejalan dengan pendapat Pendapat ini diperkuat oleh Barelson dan Steiner dalam Gunarsa (1989:92), bahwa: "Motivasi adalah kekuatan dari dalam diri untuk menggerakkan dan mengarahkan atau membawa tingkahlaku ke tujuan. Sesuai dengan pendapat tersebut jelas terlihat bahwa motivasi merupakan kumpulan-kumpulan perasaan, kesenangankesenangan, kecenderungan, dan dorongan insting, yang menampak sebagai minat yang tercipta sebagai tindakan atau perlakuan untuk mencapai tujuan tertentu". Berdasarkan kutipan tersebut fungsi motivasi adalah mendorong manusia untuk berbuat, menentukan arah perbuatan, untuk mencapai tujuan dan menyeleksi perbuatan yakni perbuatan mana yang akan dikerjakan. Jelas bahwa tanpa adanya motivasi yang baik dari siswa, maka kemauan dan keseriusan siswa dalam berlatih ataupun bertanding akan berkurang. Motivasi adalah pendorong yang menjadikan terealisasinya aktivitas. Munculnya keinginan untuk beraktivitas menunjukkan adanya motif pendorong pelaku aktifitas tersebut. Sejak lahir manusia telah membawa motif-motif tertentu. Dengan motif itu individu berusaha memenuhi kebutuhankebutuhannya, terutama untuk kelangsungan hidupnya. sehingga dengan motivasi baik, pencapaian prestasi akan dilakukan secara optimal.

Jadi salah satu usaha untuk meraih hasil yang baik dalam olahraga saat ini akan ditentukan oleh keadaan motivasi siswa, baik motivasi instrinsik maupun ekstrinsik, di SD Negeri 007 Kampung Teluk Merbau Kec. Dayun Kab. Siak keadaan motivasi siswa sudah dapat diklasifikasikan Cukup jadi diharapakan dengan keadaan motivasi yang seperti itu diharapkan dapat membantu dalam pencapaian prestasi yang lebih tinggi.

Dapat dilihat secara keseluruhan tingkat capaian dukungan orang tua yang diperoleh sebesar 64,7\%. Artinya bahwa tingkat capaian dukungan orang tua terhadap kegiatan ekstrakurikuler bolavoli mini yang 
95 Pelaksanaan aktivitas pengembangan diri olahraga bola voli mini di SD 007 Kampung Teluk Merbau- Iska Noviardila

ada di SD Negeri 007 Kampung Teluk Merbau

Kec. Dayun Kab. Siak pada klasifikasi Cukup.

Menurut Sudjana (1989:129) bahwa

klasifikasi tingkat capaian antara 65-79\% berada pada kategori Cukup.

Dukungan orang tua merupakan faktor yang sangat penting dalam memotivasi anak dalam pencapaian prestasi yang optimal. Hal ini dikarenakan bahwa orang tua lebih banyak mengetahui tentang perkembangan anaknya, apakah anak tersebut mempunyai minat, bakat dalam kegiatan ekstrakurikuler, dan apabila diketahui tentang minat tersebut, maka seharusnya orang tua memberikan dukungan moral atau materi untuk memacu terlaksananya kegiatan ekstrakurikuler di sekolah. Kegiatan ini diharapkan agar nantinya dapat menguasai keterampilan serta berprestasi, karena salah satu wadah untuk menyalurkan minat dan bakat siswa dalam cabang olahraga tersebut. Melalui kegiatan ekstrakurikuler pendidikan jasmani.

Berdasarkan hasil tersebut, jelas bahwa dukungan sangat diperlukan dalam memberi motivasi dan memberikan bimbingan kepada anak. Namun di SD Negeri 007 Kampung Teluk Merbau Kec. Dayun Kab. Siak, dukungan orang tua belum terlaksana secara penuh, untuk itulah diharapakan orang tua lebih dapat memberikan waktu untuk anaknya dalam mengembangkan bakat, yang salah satunya adalah pada kegiatan ekstrakurikuler bolavoli mini. Dengan adanya dukungan orang tua diharapkan pencapaian prestasi bisa terlaksana secara optimal.

\section{KESIMPULAN}

Adapun kesimpulan dan saran dalam penelitian ini yaitu sebagai berikut

Berdasarkan hasil penelitian yang di lalkukan di SD Negeri 007 Kampung Teluk Merbau Kec. Dayun Kab. Siak maka dapat ditarik kesimpulan:

1. Tingkat capaian Motivasi siswa pada kegiatan ekstrakurikuler bolavoli mini di SD Negeri 007 Kampung Teluk Merbau Kec. Dayun Kab. Siak berada pada klasifikasi Cukup, yaitu dengan tingkat capaian sebesar 51,7\%. Artinya bahwa Motivasi siswa terhadap kegiatan ekstrakurikuler sudah Kurang.

2. Tingkat capaian dukungan orang tua siswa terhadap kegiatan ekstrakurikuler bola voli mini di SD Negeri 007 Kampung Teluk Merbau Kec. Dayun Kab. Siak berada pada klasifikasi baik, yaitu dengan tingkat capaian jawaban responden mencapai 64,7\%. Artinya bahwa dukungan orang tua siswa terhadap kegiatan bolavoli mini di SD Negeri 007 Kampung Teluk Merbau Kec. Dayun Kab. Siak dalam klasifikasi Cukup.

Berdasarkan temuan penelitian ini, maka peneliti mengemukakan beberapa saran yaitu kepada :

1. Kepala Sekolah yang ada di SD Negeri 007 Kampung Teluk Merbau Kec. Dayun Kab. Siak dalam rangka meningkatkan prestasi bolavoli mini diharapkan agar memberikan dukungan, baik 
96 Pelaksanaan aktivitas pengembangan diri olahraga bola voli mini di SD 007 Kampung Teluk Merbau- Iska Noviardila

itu dalam penyediaan sarana dan prasarana, maupun dukungan moril, dan diharapakan juga kepala sekolah bisa bekerjasama dengan berbagai pihak dalam hal penyediaan sarana dan prasarana.

2. Siswa SD Negeri 007 Kampung Teluk Merbau Kec. Dayun Kab. Siak yang ikut kegiatan ekstrakurikuler bolavoli mini agar bisa mempertahankan motivasinya terhadap kegiatan ekstrakurikuler bolavoli mini, karena itu sangat membanu dalam pencapaian prestasi yang maksimal.

3. Orang tua siswa agar lebih meningkatkan perhatian terhadap anaknya yang mengikuti kegiatan ekstrakurikuler, baik dengan memotivasi, membantu penyediaan prasarana, dan juga dalam hal penguatan mental serta pengawasan dalam hal kesehatan dan gizi.

4. Pengurus PBVSI agar memberikan perhatian yang serius terhadap pembinaan bolavoli mini yang ada di sekolah, demi terciptanya atlet usia dini, yang berpotensi untuk menjadi atlet masa depan.

\section{DAFTAR PUSTAKA}

Departemen Pendidikan dan Kebudayaan, (1993), Pedoman Bimbingan Siswa Dalam Kegiatan Ekstra Kurikuler, Depdikbud. Jakarta

Harsono, (1986). Ilmu Coaching Umum, PIC KONI Pusat. Jakarta
HP. Suharno, (1982). Ilmu Coaching Umum, IKIP Yogyakarta

Suharno, (1982). Ilmu Kepelatihan Olahraga, FPOK IKIP Yogyakarta

Rukmana, Kamli, (1990). Latihan Volli Mini, Jakarta

Sarumpaet, A. (1986). Pendidikan Olahraga, FPOK IKIP Padang

TAP MPR, (1999) Tentang GBHN, Depdikbud. Jakarta

Hendri Guntur Taringan. 1982. Menulis Sebagai Suatu Keterampilan Berbahasa. Bandung: Aksara

Semi, Antar. 1990. Menulis Efektif. Padang: Angkasa Raya.

Noviardila, Iska, (2016) Pengaruh Penerapan Pendekatan Pembelajaran Berbasis Aktivitas Siswa (Pbas) Dan Konvensional Serta Motivasi Belajar Terhadap Kemampuan Motorik Siswa Sekolah Dasar Negeri Kampung Teluk Merbau Kec. Dayun Kab. Siak, TESIS : UNP 